rev.relac.int.estrateg.segur.6(2):63-88,2011

\title{
COOPERACIÓN INTERNACIONAL DESCENTRALIZADA PARA LA GESTIÓN PÚBLICA DEPARTAMENTAL Y MUNICIPAL EN COLOMBIA*
}

\author{
Jahir Alexander Gutiérrez Ossa**
}

\section{RESUMEN}

El artículo estima las posibilidades que tienen los departamentos y municipios en Colombia de apropiar los principios pragmáticos de la cooperación internacional descentralizada como base para la fundamentación del

* $\quad$ Este artículo es producto del proyecto de investigación: "Capacidades Institucionales Públicas para la Competitividad Territorial Internacional de las Sub-regiones del Departamento de Antioquia", financiado por la Vicerrectoría de Investigaciones de la Escuela de Administración Pública (ESAP), entre agosto y diciembre de 2010. Investigación adscrita al Grupo de Investigación en Política, Derecho y Gestión Pública, registrado en Colciencias en categoría A, de la Escuela de Administración Pública (ESAP), Bogotá.

** Economista de la Universidad de Medellín, Colombia, (PHD) en Administración Pública, Atlantic International University (AIU) Hawái (USA), Magíster en Desarrollo Regional y Local, Universidad Pontificia Bolivariana, Medellín, Colombia. Estudiante de la Especialización en Sistemas de Información Geográfica (SIG), Universidad San Buenaventura, Medellín, Colombia. Docente e investigador, Facultad de Administracion, Universidad CES en Medellín y Universidad del Rosario en Bogotá, Colombia. Líder del Grupo de Investigación en Gestión Empresarial de la Facultad de Administración CES, registrado en Colciencias, y miembro del Grupo de Investigacion en Política, Derecho y Gestión Pública de la Escuela de Administración Pública (ESAP), Bogotá, y del Grupo de Investigación en Perdurabilidad empresarial en las empresas (GIPE) categoría A1 de la Universidad del Rosario, Bogotá. algutierrez@ces.edu.co, teléfono: 4440555, extensión 1411, dirección: Calle 10A No 22 - 04, Bl. 4 of. 04. 
modelo de gestión pública local-global. De manera reciente, la posición estatal ha dado un viraje importante hacia la promoción directa de los principios de la cooperación al interior de la estructura de los entes territoriales. La puesta en marcha del tema depende de la claridad y entendimiento que atiendan al respecto las corporaciones públicas locales (concejos), y regionales (asambleas), conforme a la agenda programática definida por iniciativa propia, o sobre la perspectiva en materia derivada de los planes de desarrollo. Fruto de dicho semblante, hoy se destacan dos ciudades con sus respectivos gobiernos departamentales: Bogotá-Cundinamarca y Medellín-Antioquia, las cuales han avanzado en el marco territorial de la cooperación descentralizada. Falta por lo pronto llevar este programa a instancias territoriales menos privilegiadas.

Palabras clave: Estructura y campos gubernamentales, eficiencia, relaciones intergubernamentales, contactos internacionales.

\section{ABSTRACT}

This article estimates the possibilities of the departments and municipalities in Colombia for appropriating the pragmatic principles of international decentralized cooperation, as basis for the foundation of the model of public local-global governance. Recently, the State's position gave an important swing towards the direct promotion of the principles of cooperation in the inside of the structure of local entities. The launching of the idea depends on the clarity and understanding to address the matter by the local (councils) and regional (assemblies) public corporations, in accordance with a programmatic agenda defined by its own initiative or on the perspective of the subjects derived from the development plans. As a result, nowadays two capital cities with their respective departments stand out: Bogotá-Cundinamarca and MedellinAntioquia, as they have moved forward in the territorial framework of decentralized cooperation, only needing its transit in the less privileged territorial entities.

Key Words: Structure and Scope of Government, efficiency, Intergovernmental Relations, International contacts

\section{RESUMO}

O artigo faz uma estimativa das possibilidades dos departamentos e municípios na Colômbia de monopolizar os princípios pragmáticos da cooperação internacional descentralizada como base para a fundamentação do modelo de gestão pública local-global. Recentemente, a posição estatal deu uma virada importante que visa incentivar a aplicação direta dos princípios da cooperação no interior da estrutura das instituições territoriais. $O$ andamento desta questão vai depender da clareza e entendimento que houver entre as corporações públicas locais (conselhos) 
e regionais (assembléias), de acordo a uma agenda programática definida por iniciativa própria ou sobre uma perspectiva derivada dos planos de desenvolvimento. Na atualidade destacamse, como resultado deste panorama, duas cidades com seus respectivos governos departamentais: Bogotá-Cundinamarca e Medellin-Antióquia, as quais avançam no âmbito territorial da cooperação descentralizada. No momento, ainda falta poder implantar este programa para outras áreas menos favorecidas do território.

Palavras chave: Estrutura e campos governamentais, eficiência, relações intergovernamentais, contatos internacionais.

\section{INTRODUCCIÓN}

Los entes territoriales han sido delegados para la puesta en marcha y vigencia de la cooperación internacional descentralizada. En ellos, están trazados los lineamientos de trabajo para obtener el máximo provecho de la cooperación directa extendida bajo dicha tutela. Si bien es una premisa que viene impulsada a escala global, la materialización de la misma en el caso colombiano, sólo ha llegado a tocar las puertas de los territorios centrales-tradicionales como BogotáCundinamarca y Medellín-Antioquia, entre algunos otros.

El acogimiento efectuado por los mencionados territorios lógicamente era de esperarse. No obstante, la pretensión de la cooperación internacional descentralizada es llegar a colmar las expectativas, precisamente, en las áreas territoriales en las que las necesidades y urgencias implican una recomposición institucional y orgánica de la gestión pública local. Es la cooperación, quien expone dicha posibilidad, conforme a la sensibilidad que el tema crea a escala local, y que por lo tanto, es importante apreciar el entorno que recrea.

La medida de proliferación de las referencias sostenidas en la cooperación internacional descentralizada debe estar en plena coordinación con la estructura institucional de los entes que representan las entidades territoriales. Para el caso en cuestión, las Asambleas departamentales y los Concejos municipales, representan claramente el manifiesto que con respecto a la vigencia del tema representa para uno de los corporados, además claro está, del potencial que los planes de desarrollo, aprobados o discutidos, expongan frente al asunto.

Los entes territoriales menos favorecidos son el espacio propicio para establecer las calidades y condiciones de la cooperación internacional, en tanto, las condiciones de los mismos prescriben un exagerado cuerpo de gestión institucional, que impulsa a estos territorios, a responder de manera colegiada ante las contingencias y dificultades que constituye administrar entes locales y regionales con dificultades de toda especie, siendo ellas, un importante argumento para elaborar el marco de referencia, que en cuanto a cooperación, están en capacidad de disponer y de involucrar como indicador de gestión local-global. 
En suma, la cooperación internacional descentralizada favorece las condiciones institucionales que, por estar constituidas en el epílogo de un estado de referencias en ocasiones constitucionales y de otras índoles como las geográficas o sociales, deterioran la capacidad de gestión pública local de los entes, cuyo escenario de circunstancias es mucho más propicio para establecer los rangos de desempeño que a bien cuenta se podrían apreciar a través de la cooperación entre los mismos, convertida en el tiempo en un mecanismo evaluador.

El artículo, está compuesto por los siguientes puntos de referencia: en primer lugar del contexto en que se desenvuelve la cooperación internacional a escala nacional con el propósito de evidenciar elementos propicios para su afianzamiento a nivel local-territorial. En segundo lugar, la caracterización y estructura en la que se basa la (CID) para proveer espacios de gestión pública local en los entes territoriales; en tercer lugar, presenta la manera como es atendida la cooperación internacional en la gestión pública departamental y municipal, en Cundinamarca-Bogotá y Antioquia-Medellín.

\section{PERSPECTIVAS DE LA COOPERACIÓN INTERNACIONAL CENTRAL Y DESCENTRALI- ZADA EN COLOMBIA}

El tema de la cooperación internacional y de los organismos internacionales en la administración pública colombiana ha sido abordado de manera general y tangencial por parte de las administraciones públicas territoriales, tal es así, que aún el Estado está al enfrente del tema, bajo la tutela de Acción Social (AS), de todo lo concerniente a asistencia, ayuda, financiación, préstamos o contratación provenientes de la cooperación. Sin embargo, en la Constitución y la ley existen normas y artículos que permiten analizar el campo de acción de los entes departamentales y municipales en dicha materia, que con acierto podrían contribuir para desarrollar una mejor administración pública. Se puede afirmar que:

La importancia de la Cooperación en el apoyo al proceso de desconcentración y descentralización, reinstaurada la democracia, se ha hecho evidente el interés de diversos actores por promover estos temas. En algunos casos son los propios gobiernos de Europa y Norteamérica los que quieren dar a conocer sus experiencias. En otros, son autoridades subnacionales (como gobiernos regionales y locales), las que además de tener crecientemente contemplados en sus presupuestos un ítem para cooperación, especialmente con sus similares del Tercer Mundo, muchas veces han creado empresas adheridas, por medio de las cuales se proyectan objetivos de cooperación con otros estrictamente comerciales. Las Agencias Multilaterales también han empezado crecientemente y con mucha fuerza a canalizar recursos para programas de fortalecimiento de gobiernos regionales y locales, aquí están el Banco Mundial, el BID, el Sistema de N.N.U.U, y aún cuando pueda corresponder a otra categoría institucional, la Comunidad Europea. Además de estos macro actores, también se ha despertado el interés de fundaciones 
privadas, universidades, ONG establecidas en los países industrializados por incorporar entre sus líneas de trabajo proyectos insertos en este tema (Abalos, 2006, pp. 4-5).

Frente a la estructura global de la cooperación internacional en el país, han sido más las acciones dirigidas a definir el campo jurídico de la cooperación, que a una definición clara sobre cómo los entes territoriales podrían participar en dicha relación. Si bien, las condiciones jurídicas y normativas han hecho un aporte relevante con respecto a la importancia de la cooperación, esta aún no goza de respaldo unánime, paradójicamente, en las mismas instancias territoriales, que alegando dificultades inherentes a la gestión que actualmente tienen, podrían igualmente atender este llamado como una carga más a su ya extralimitada administración local. Sin embargo, son estos parámetros jurídicos los que claramente han develado el faltante de análisis y discusión local. (Ver cuadro1).

\section{Cuadro 1: Estructura jurídica y régimen de cooperación internacional en Colombia.}

\begin{tabular}{|l|l|}
\hline Estructura jurídica & \multicolumn{1}{c|}{ Régimen } \\
\hline $\begin{array}{l}\text { El Artículo } 78 \text { del } \\
1989 .\end{array}$ & $\begin{array}{l}\text { Atribuía a la División Especial de Cooperación Técnica Internacio- } \\
\text { nal, DECTI, del Departamento Nacional de Planeación, las funcio- } \\
\text { nes de orientar, promover y realizar, en coordinación con los } \\
\text { organismos y entidades pertinentes, la formulación de políticas, pla- } \\
\text { nes, programas y proyectos en materia de cooperación técnica in- } \\
\text { ternacional, de acuerdo con la política exterior del país, y los } \\
\text { requerimientos del Plan Nacional de Desarrollo Económico y Social }\end{array}$ \\
\hline $\begin{array}{l}\text { Artículo 9 de la } \\
\text { tica de Colombián. }\end{array}$ & $\begin{array}{l}\text { Establece que las relaciones exteriores del Estado se fundamentan } \\
\text { en la soberanía nacional, en el respeto a la autodeterminación de } \\
\text { los pueblos y en el reconocimiento de los principios del derecho } \\
\text { internacional aceptados por Colombia. Artículos 9, 226, 227, 311, } \\
313 \text { numeral 2 y 6, de la Constitución Política de Colombia y los } \\
\text { Artículos de la Ley No. 136 de 1994, la Ley No. 162 de 1994 y la } \\
\text { Ley No. 388 de 1997; la Resolución 2861 de la XXVI Asamblea } \\
\text { General del 20 de diciembre de 1971, sesión plenaria de la Organi- } \\
\text { zación de las Naciones Unidas }\end{array}$ \\
\hline $\begin{array}{l}\text { El Artículo 14 del } \\
\text { Decreto 2126 de } \\
1992 .\end{array}$ & $\begin{array}{l}\text { Atribuía a la Dirección General de Cooperación del Ministerio de } \\
\text { Relaciones Exteriores las funciones de articular la cooperación in- } \\
\text { ternacional con los objetivos generales y estrategias de la política }\end{array}$ \\
\hline
\end{tabular}




\begin{tabular}{|c|c|}
\hline & $\begin{array}{l}\text { exterior del país, y la capacidad de proponer las pautas de ne- } \\
\text { gociación en la materia y orientar, promover y coordinar con las } \\
\text { entidades correspondientes la cooperación internacional; poste- } \\
\text { riormente en el año 1995, mediante el Decreto } 1347 \text { de } 1995 \text {, se } \\
\text { creó el Consejo Nacional de Cooperación Internacional con las } \\
\text { funciones de recomendar los lineamientos generales que deben } \\
\text { guiar las demandas de cooperación internacional y las acciones de } \\
\text { cooperación horizontal que realice el país, también las funciones } \\
\text { de estudiar y aprobar los proyectos de cooperación internacional } \\
\text { no reembolsable que sean presentados por las instancias naciona- } \\
\text { les, a través de la División Especial de Cooperación Técnica Inter- } \\
\text { nacional del Departamento Nacional de Planeación; y de coordinar } \\
\text { las necesidades específicas de cooperación que requiere el país y } \\
\text { buscar acciones concretas vinculadas con éstas y promover activi- } \\
\text { dades de cooperación horizontal. Así mismo, se instituyó el Comi- } \\
\text { té Intersectorial de Cooperación Internacional como la instancia } \\
\text { de enlace y articulación de las entidades demandantes de coope- } \\
\text { ración internacional y oferentes potenciales de cooperación técni- } \\
\text { ca, adscrito al Departamento Nacional de Planeación }\end{array}$ \\
\hline $\begin{array}{l}\text { El Documento } \\
\text { CONPES } 2768 \\
\text { Política Nacional } \\
\text { de Cooperación } \\
\text { Internacional } \\
\text { MINRELACIONES } \\
\text { EXTERIORES - } \\
\text { DNP: DECTI del } \\
22 \text { de marzo de } \\
1995 .\end{array}$ & $\begin{array}{l}\text { Propone la creación de una Agenda de Cooperación Internacional } \\
\text { adscrita al Departamento Nacional de Planeación. De esta forma, } \\
\text { mediante la Ley No. } 318 \text { del } 20 \text { de septiembre de } 1996 \text { se creó la } \\
\text { Agencia Colombiana de Cooperación Internacional -ACCl- la cual } \\
\text { se encargará de coordinar, administrar y promover los recursos de } \\
\text { cooperación internacional técnica y financiera, no reembolsable, que } \\
\text { reciba y otorgue el país así como de los recursos que se obtengan de } \\
\text { operaciones de condonación de deuda. Es decir, la Agencia será la } \\
\text { entidad rectora encargada de canalizar la totalidad de recursos y las } \\
\text { solicitudes de cooperación internacional. } \\
\text { Con el ánimo de fortalecer la cooperación internacional la ley creó } \\
\text { el Fondo de Cooperación y Asistencia Internacional con el propósi- } \\
\text { to de apoyar iniciativas tendientes a incrementar los flujos de co- } \\
\text { operación horizontal. Así mismo, el Comité Intersectorial de } \\
\text { Cooperación Internacional será el encargado de actuar como ins- } \\
\text { tancia de enlace y coordinación de las solicitudes de cooperación } \\
\text { formuladas por las entidades demandantes de recursos de coopera- } \\
\text { ción internacional. }\end{array}$ \\
\hline
\end{tabular}




\begin{tabular}{|c|c|}
\hline & $\begin{array}{l}\text { El Gobierno Nacional, a través de la Agencia, definirá las priorida- } \\
\text { des y proyectos a ser financiados de acuerdo con el Plan Nacional } \\
\text { de Desarrollo y de esta forma, revertir la tendencia que Colombia } \\
\text { ha tenido en los últimos años como receptor y mostrarse más como } \\
\text { demandante y negociador }\end{array}$ \\
\hline $\begin{array}{l}\text { El Documento } \\
\text { CONPES } 2968 \\
\text { de } 1997 .\end{array}$ & $\begin{array}{l}\text { Trae una nueva orientación y enfoque de la cooperación internacio- } \\
\text { nal mediante la definición de los lineamientos de política que per- } \\
\text { mitan la consolidación de la cooperación como instrumento de apoyo } \\
\text { al desarrollo. } \\
\text { Las intenciones contempladas en los documentos CONPES de los } \\
\text { años } 1995 \text { y } 1997 \text {, fueron cristalizadas con la expedición de la Ley } \\
\text { No. } 318 \text { de } 1996 \text { y el Decreto } 2807 \text { de 1997, mediante los cuales } \\
\text { se creó la Agencia Colombiana de Cooperación Internacional - ACCI } \\
\text { y se establecieron sus estatutos. } \\
\text { Mediante el Decreto } 1320 \text { de julio } 13 \text { de } 1999 \text {, se adscribió al Mi- } \\
\text { nisterio de Relaciones Exteriores. } \\
\text { Mediante el Decreto } 1540 \text { de junio } 6 \text { de } 2003 \text {, se adscribió al De- } \\
\text { partamento Administrativo de la Presidencia de la República. } \\
\text { Cabe resaltar que bajo la Ley } 318 \text { de } 1996 \text {, todas las entidades del } \\
\text { Estado estaban obligadas a canalizar la totalidad de las solicitudes } \\
\text { de cooperación internacional a través de la ACCl }\end{array}$ \\
\hline $\begin{array}{l}\text { El Decreto } 1942 \\
\text { del } 11 \text { de julio } \\
\text { de } 2003 \text { y El De- } \\
\text { creto } 2467 \text { ex- } \\
\text { pedido por el } \\
\text { Presidente de la } \\
\text { República el } 19 \\
\text { de julio de } 2005 .\end{array}$ & $\begin{array}{l}\text { Marco normativo de la cooperación internacional en Colombia, con } \\
\text { base en sus facultades constitucionales y legales, en especial de las } \\
\text { señaladas en el numeral } 15 \text { del Artículo No. } 189 \text { de la Constitución } \\
\text { Política, y en los literales b) y e) del Artículo } 2^{\circ} \text { de la Ley No. } 790 \text { de } \\
2002\end{array}$ \\
\hline Otros & $\begin{array}{l}\text { Artículo 241, inciso } 10 \text { C. N. Organismos Internacionales. } \\
\text { Artículo 13, inciso } 4 \text { de la Ley No. 80, derogado por la Ley No. } \\
\text { 1150/95 de presupuesto. }\end{array}$ \\
\hline
\end{tabular}




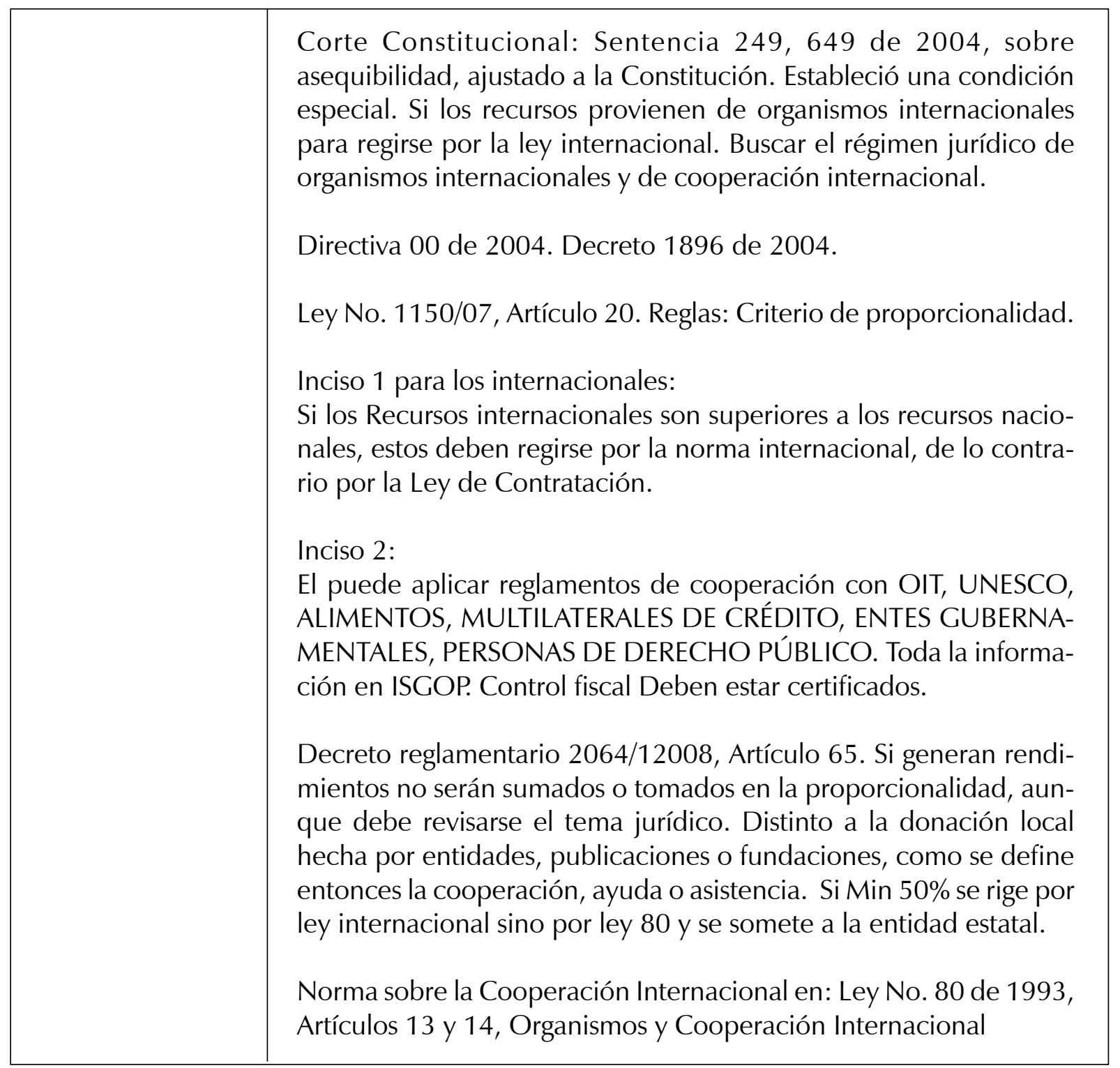

Fuente: Elaboración propia a partir de la Constitución, leyes y Documentos CONPES.

Al respecto, la cuestión radica en definir los elementos que se requieren para que las administraciones territoriales tomen fundamento con respecto a la cooperación internacional, y de allí, establezcan una hoja de ruta con la cual puedan identificar una agenda de trabajo, con la que a su vez, puedan compulsar la estructura programática de los planes de desarrollo acontecidos en ellas o la proyección estratégica, en la que tuviera lugar sus iniciativas de administración y gestión pública. Cabe apreciar, que las prerrogativas vinculadas con la cooperación tiene, entre otras posibilidades, el procurar que las administraciones locales fortalezcan sus instituciones. 
Ana Cirera hace énfasis en lo siguiente: "Es reflexionar sobre las repercusiones que la dimensión global de las políticas de cooperación, y sus sistemas de evaluación, tienen sobre los Gobiernos modernos y que condiciona sus formas de gobernanza y gobernabilidad" (Cirera, 2009)

La estimulación hecha por el Estado central, y que ha sido ampliamente difundida para acercar los procesos de cooperación a los entes territoriales, debe tener una amplia respuesta por parte de estos últimos, toda vez que son ellos quienes deben auspiciar los mecanismos con los cuales puedan desatascar la constante en la baja gestión pública, que los hace paradójicamente vulnerables ante los cambios de dirección definidos en la administración pública, que bajo razones claras no tienen la capacidad de afrontar, debido a que dichas administraciones sólo estiman conveniente el cumplimiento de sus funciones básicas. Se puede hacer la siguiente comparación:

De otra parte, los gobiernos locales han generado tal dinámica en los temas de cooperación que los mismos Gobiernos Nacionales han propuesto espacios para apoyar estas iniciativas. Escenarios como los propuestos por la Agencia Española de Cooperación Internacional en programas como MUNICIPIA, que apuntan a mejorar las capacidades institucionales, sociales y económicas de los municipios, son fundamentales para avanzar en el desarrollo urbano y regional (Garzón, 2008, p. 8).

De ahí que no solo basta enfilar el interés en procurar que el Estado contextualice aún más las prerrogativas de la cooperación internacional, central o descentralizada, así mismo, es necesario conocer el estado de balance que cada región del país presenta a la luz del tema, y qué tanto de dicha manifestación puede ser traducida en la definición de áreas de trabajo concretas, con las que cada propuesta de plan de desarrollo, o pretensiones inherentes a este último, tengan como talante y objetivo afianzar el alcance de los resultados, la interacción con estamentos y órganos de cooperación con los que la administración local pueda impactar de manera eficiente:

El nuevo dinamismo económico y social de las regiones subnacionales se manifiesta en el plano de la mundialización, en cuyo entrecruzamiento de relaciones surgió de manera progresiva en los últimos dos decenios la llamada paradiplomacia - término con que los especialistas denominan las acciones internacionales de las entidades de gobierno no central, algunas de las cuales, lo mismo en los países industrializados que en las naciones en vías de desarrollo, se han tornado muy activas en la promoción externa de los asuntos socioeconómicos, culturales o de seguridad que son de su competencia (Godínez, 1999, p. 2)ํ․

La propuesta se ajusta a los requerimientos de las agencias de cooperación departamental, al igual que a los de las oficinas o secretarías de las administraciones públicas encargadas o

1. Véase F. Aldecoa y M. Keating (editores), Paradiplomacy in Action. The Foreign Relations of Subnacional Governmets, Frank Cass, Londres, 1999. 
relacionadas con dicha materia, quienes hoy, pese al avance de la gestión en cooperación internacional, no la ven como un cuerpo angular o colegiado en el ejercicio de la administración pública, y ni que decir, cuando se habla de ellas como bastión fundamental para consolidar el papel de las administraciones locales, a través de la gestión pública local, conforme a la guía y los criterios planteados por medio de la cooperación internacional. Anota Torrijos:

[...] Una diplomacia que se aleja del centro estatal y que podría definirse como aquel conjunto de iniciativas exteriores de tipo político, social, económico, cultural, etc., diseñadas, emprendidas, reguladas y sostenidas por colectividades territoriales (las regiones) que proclaman y despliegan una capacidad de actuación propia (Torrijos 2000, pp. 20-21).

Esta es una iniciativa que fácilmente puede replicarse en cualquier instancia o estamento que tenga claro que, el involucramiento de la gestión pública local a la cooperación central y descentralizada, se hace con el propósito de contribuir a un orden institucional que tiene como eje contribuir para que las actividades e impactos institucionales en diferentes aspectos tengan el resultado esperado, y que si por cuenta de ello las administraciones terminan favorecidas, el éxito sería rotundo. Por ende, los corporados deben claramente incentivar el desarrollo y la puesta en marcha de agendas de cooperación, en especial, las que corresponden a temáticas cuya naturaleza escapan a la perspectiva local o nacional, requiriendo una mirada externa que sería constructiva e ilustrativa tenerla vía cooperación internacional. (Ver cuadro 2).

\section{Cuadro 2: Funciones de la (CID)}

Los principales efectos que está teniendo la COD (Cooperación Oficial Descentralizada), sobre el nuevo modelo de Cooperación Internacional al Desarrollo y que propiciará un mayor protagonismo de la Administración Local en el mismo son:

Desde el punto de vista de los donantes. La COD potencia la participación de agentes públicos no centrales (locales y regionales), en la definición/ejecución de políticas de cooperación internacional.

Desde el punto de vista de los beneficiarios. Se comienza a considerar como sujeto básico receptor de cooperación al desarrollo no sólo a la Administración Pública Nacional sino también a otros organismos públicos descentralizados (regionales e incluso locales). Incluso se fortalece la idea de establecer como sujetos receptores a agentes privados (con o sin ánimo de lucro) 
Desde el punto de vista del agente ejecutor. Se comienza a valorar como una medida de mayor eficacia y eficiencia una mayor participación de los agentes privados en la ejecución de la cooperación al desarrollo en sus distintas tipologías (ayuda humanitaria, proyectos, cooperación técnica...)

Desde el punto de vista de la identificación. Se comienza a considerar como prioritario e imprescindible la participación de las poblaciones, sociedad civil y gobiernos locales en la definición de las acciones a realizar a través de las políticas de cooperación internacional. Surgen por tanto nuevas metodologías de evaluación e identificación muy cercanas a las poblaciones locales a través de las cuales se intenta dar mayor protagonismo a la voluntad popular frente a la voluntad gubernamental de carácter nacional o central.

Desde el punto de vista de las tipologías de cooperación. Se enfatiza el uso de instrumentos más adaptados y flexibles a la gestión de agentes locales (proyectos, canalización a través de ONG's, etc...) frente a instrumentos más complejos y menos accesibles a la gestión local (condonación de deuda, ayuda en divisas, etc.).

Desde el punto de vista sectorial. Se prioriza y comienza a tener en consideración nuevas actuaciones sectoriales en el ámbito de la cooperación internacional al desarrollo que cobran mayor fuerza como elementos motrices del desarrollo (fortalecimiento institucional, políticas territoriales, etc.).

Fuente: Tomado de Palomo (2005, p. 4).

Es importante señalar que, la cooperación internacional se orienta hoy a enfocar la ayuda internacional hacia los problemas estructurales que afrontan la naciones de menor desarrollo y a complementar el esfuerzo nacional orientado a la equidad social y el desarrollo humano; y se enmarca en los principios que orientan la agenda internacional: reconciliación y gobernabilidad democrática, responsabilidad compartida, protección del medio ambiente, fortalecimiento del recurso humano para el empleo y la solidaridad internacional. No obstante, la fuerza adquirida por la cooperación internacional descentraliza hacia campos puntuales, vinculados a intereses locales y regionales, se muestran como el escenario futuro de la cooperación internacional, tras de los cuales están siendo generadas nuevas fuentes y recursos de financiación.

\section{CARACTERIZACIÓN DE LA COOPERACIÓN INTERNACIONAL DESCENTRALIZADA EN COLOMBIA}

El Estado en Colombia ha asumido con vehemencia el papel de agente económico con respecto a su relación con los ciudadanos, muestra de ello, ha comenzado a delegar y dejar a un lado 
actividades que hasta hace poco eran de correspondencia directa a su quehacer como el mismo bienestar de la población, dejando el margen de maniobra a cargo de los entes departamentales y municipales. De hecho, se señala que el Estado debe considerar también su propio equilibrio y estabilidad como figura internacional, como ha sido señalado por organismos de diferentes corrientes y tendencias a escala internacional. Aunque está no es la discusión central. Al respecto, se han hecho desde la misma (AS), anterior Agencia Colombiana de Cooperación Internacional $(\mathrm{ACCl})$, las siguientes preguntas:

Ante la difícil situación económica, ¿̇hasta qué punto la Cooperación Internacional es la tabla de salvación para los departamentos y municipios? En la actualidad se están desarrollando diversas iniciativas tendientes a fortalecer a los Departamentos y a los Municipios con el apoyo de la República Federal de Alemania y la Unión Europea. Las actividades que se están realizando incluyen la gestión y las finanzas, sin embargo, la cooperación internacional se ubica más en proveer herramientas para mejorar el quehacer de las administraciones en lugar de la asignación de recursos. ¿Un municipio puede presentar un proyecto para la cooperación internacional?, ¿las entidades del Estado pueden recurrir de manera directa a las Embajadas y organizaciones multilaterales? El conducto regular lo constituye la $\mathrm{ACCl}$, quien asegura una posición integrada de nuestro país, garantiza una interlocución y una unidad de criterio, evita duplicidad de acciones y facilita la coordinación con los cooperantes. Las entidades que así lo requieran pueden contactar las embajadas para obtener información adicional sobre las áreas de interés, los tipos de proyectos que se están apoyando en un momento determinado, o las capacidades de las entidades similares en los respectivos países, así como, para la exploración de aquellas líneas que manejan directamente las Embajadas y las Representaciones de Organismos Internacionales. (Agencia Colombiana de Cooperación Internacional -ACCI. Doc. Institucionales Documentos de trabajo Colombia Joven, 2002, p. 2).

El acercarse a la cooperación internacional es un ejercicio calificativo de hasta donde se puede llegar en la gestión no sólo en cuestión de recursos, sino en la capacidad de mostrar resultados concretos. Más que observarla como una salida, es una gran oportunidad la que tienen los entes territoriales para poder encarar lo que se les presenta en cuanto a la evaluación y medición de sus capacidades de respuesta ante las demandas locales y solicitudes de los ciudadanos, que ya no se traducen en la eficiencia política, sino en la eficiencia de la administración pública, revestida con la capacidad de impulsar derogatorias a cargos públicos o a la conducción de los burgomaestres a dar descargos públicos ante la ciudadanía y la misma justicia. Tras la (CID) se replantea la capacidad de gestión plena de los entes territoriales. Señala al respecto Del Huerto:

El surgimiento y desarrollo del Programa URB-AL de cooperación de la Comisión Europea con América Latina se comprende en el marco de la emergencia de tres fenómenos: nuevos enfoques en la cooperación internacional, cambios en el patrón tradicional de gestión local, y el proceso reciente de internacionalización de ciudades y regiones. Como una opción para enfrentar las debilidades percibidas en los mecanismos tradicionales y para dar respuesta a las 
nuevas realidades internacionales surge el enfoque de la cooperación descentralizada (Del Huerto, 2005, p. 2).

En cuanto a los enfoques, se requiere de un cuerpo colegiado enfocado (Concejo y Diputados), más que a la posición o a la coalición, a la gestión desde la cual se pueda avanzar más allá de la medida política o del activo político que se tiene en el momento de ser elegido. Tendrá que abonar también el camino para ser considerado gestor de una nueva realidad en la administración pública. Estará conformado por necesidad, de personas conocedoras del mundo y de la realidad que atañe a la localidad. Las exigencias globales pasarán a ser discusión local, de igual forma, la cooperación internacional descentralizada; y se tendrá que contar con los sujetos necesarios para encauzar dicha meta como propósito de una excelente gestión pública local con entes de otras naciones y directamente, de sus propios Estados. Ferrari señala a este respecto que:

Los actores de la cooperación técnica ya no son exclusivamente los gobiernos: en todos los países de la región, y para todos los temas, proliferan organizaciones no gubernamentales nacionales o extranjeras como ejecutoras de proyectos de desarrollo, planteando, a la vez, dificultades (dado que la cooperación ya no pasa solamente a través del canal oficial gobiernodonante-gobierno) y oportunidades (ya que se multiplican las capacidades de tomar iniciativas y ponerlas en práctica, más allá de las limitaciones del gobierno). En la región, entre los actores que adquieren un papel cada vez más relevante cabe incluir los propios países de América Latina y el Caribe, ya que la Cooperación Técnica entre Países en Desarrollo (CTPD) se está convirtiendo en uno de los mecanismos que mejor acompañan los planes de desarrollo. Aunque las tendencias señaladas no son exclusivas de América Latina y el Caribe, la experiencia de la región en calidad tanto de receptor como de donante de cooperación técnica amerita ser examinada y mejor conocida, sobre todo en el ámbito de las instituciones financieras internacionales (IFIs), que aportan a la región volúmenes relativamente significativos de recursos en esta materia (Ferrari, 2003, p. 7).

Bajo estas consideraciones, se pretende analizar la capacidad que tienen los entes territoriales para hacer de la cooperación internacional, y de los organismos internacionales, una oportunidad que les permita refrendar y acrecentar la presencia e impacto a escala estatal, pero en iguales términos, en cuanto a procurar la excelente gestión en la administración pública territorial. Además de escenificar con carácter de propuesta, la articulación de las administraciones públicas territoriales, municipios y departamentos, para que estos bajo capacitación, conocimiento, condiciones y posibilidades, puedan abonar dicho camino con plena autonomía, sin reparo frente a la observancia central:

El modelo clásico de cooperación se está revaluando. Aquel modelo basado en la relación de un Estado Donante - Estado Mediador - Gobierno local receptor, en donde el primero entregaba recursos a fondo perdido con resultados poco efectivos se ha modificado por un modelo que valora la asistencia técnica, la experiencia y las tecnologías locales y los traduce en beneficios 
directos para las regiones y gobiernos cooperantes. Los Gobiernos Locales, Bogotá por ejemplo, han enfocado su política y sus estrategias de internacionalización en dos frentes que a la fecha han mostrado sus ventajas. El primero de ellos hace referencia a la cooperación descentralizada pública que se expresa en las redes de ciudades y en los acuerdos bilaterales que ha suscrito con entes territoriales de América y Europa. El segundo frente se ha centrado en las relaciones de cooperación oficial que se establecen con organismos gubernamentales ó multilaterales de Ayuda Oficial al Desarrollo (AOD) (Garzón, 2008, pp. 6-7).

En cabeza del Estado debe estar presente la proyección y vigencia de la cooperación internacional, central y descentralizada, como marco de gestión pública territorial. El allanar la senda de posibilidades por parte de este, y la apertura que como resultado se espera de la extensión de este recurso encarado en las funciones de los entes territoriales, es una excelente oportunidad para que Colombia pueda avanzar en los temas de autonomía y descentralización, por lo menos en lo que al carácter del territorio obedece. Para ello, es primordial concebir las nuevas funciones y el papel que en adelante deberían cumplir este y los entes territoriales, para posicionar a la cooperación como parámetro de la gestión de la administración pública local y regional. En el mismo sentido plantea en el Documento CONPES (2968, 1997, p.1):

Se tenía la premisa hasta hace muy poco sobre la cooperación como un instrumento para ayudar a países con un alto nivel de pobreza o de ingreso bajo, no obstante esa consideración ya cambio. Inclusive países como Chile, con un grado de desarrollo económico y social superior al de Colombia, han incrementado significativamente los recursos de cooperación. Es por ello que Colombia requiere darle un nuevo enfoque a la cooperación internacional bajo el contexto de globalización e interdependencia económica en el cual exista el concepto de corresponsabilidad entre la fuente y el país receptor. (Tomado de: Memoria de 1991 de la Agenda de Cooperación Internacional de Chile).

El esquema actual de cooperación internacional ha dejado a un lado el papel de los Estados como figuras prominentes de dicho proceso. La tendencia global es que sean las entidades locales y territoriales quienes asuman dicha representación. En atención a ello, el Estado en Colombia pretende abonar el camino para que la administración municipal asuma de manera directa dicha prelación ante organismos internacionales. Para ello, es necesario no solo considerar la posibilidad de que los entes obtengan dicha potestad, sino que de igual forma determinen las condiciones que se requieren por parte del Estado para que ello sea viable.

\section{GESTION DEPARTAMENTAL Y MUNICIPAL A TRAVÉS DE LA COOPERACIÓN INTER- NACIONAL DESCENTRALIZADA: ANTIOQUIA Y CUNDINAMARCA.}

Ambos departamentos con sus respectivas capitales han acogido el llamado por establecer un escenario de trabajo que protocolice claramente la senda de trabajo en materia de coope- 
ración internacional. Es consecuente, que en ellos se hayan dado los primeros pasos para identificarse con las expectativas promulgadas en cuanto al esquema que plantea el estado colombiano para que los entes territoriales adhieran dentro de su capacidad de gestión elementos sobre los que puedan contemplarse fundamentos claros de cooperación, particularmente descentralizada. Ahora bien, el propósito radica en evidenciar la estructura que se requiere para ello.

En Antioquia, y en Medellín, ha emergido la Red Antioqueña de Cooperación Internacional con la que se ha pretendido encaminar los esfuerzos privados y públicos con el propósito de contribuir para auspiciar el ascenso de la gestión pública local como punto de referencia desde la cooperación internacional. No obstante, el acercamiento realizado hacia la cooperación no ha tenido toda la difusión que se requiere a escala descentralizada, particularmente, en los entes territoriales en donde dicha iniciativa tendría más impacto, de lo que hasta ahora es advertido y considerado, por ser precisamente ellos, quienes requieren puntos de apoyo para afianzar los débiles estados de la gestión en sus respectivas administraciones:

La Gobernación de Antioquia, la Alcaldía de Medellín y 4 instituciones del sector privado, académico y social conforman la Red. Es la primera red de cooperación en Colombia. 10 años compartiendo experiencias en cooperación internacional permiten consolidar esta iniciativa. La Red se enmarca en el Sistema Nacional de Cooperación Internacional y en los acuerdos mundiales para la gestión de cooperación, como la Declaración de París 2005 y el Programa de Acción de ACCRA 2008, que reconocen el valor agregado de los actores locales, promueven relaciones más horizontales entre Norte y Sur, y contribuyen a la definición de agendas de trabajo concertadas. (Gobernación de Antioquia, 2010:1)

Además, el plan de desarrollo del Gobernador Luis Alfredo Ramos, "Antioquia para todos, Manos a la Obra", expresa claramente el interés para que pueda constituirse una referencia expedita en cuanto a la cooperación internacional. De ahí que dicha mirada haya servido para la disposición de una línea estratégica argumentativa, para inducir a los entes territoriales en la búsqueda de alternativas provistas por la cooperación, como una realidad directa a sus actividades de gestión local. Esta circunstancia contribuye a abandonar la idea que habían dejado las últimas administraciones con respecto al poco interés que para ellas representaba el campo de la cooperación. No obstante, Antioquia es uno de los departamentos del país que más requiere auspiciar una perspectiva seria, para implementar la cooperación descentralizada como campo de gestión pública local. Indica Cavestany:

Los motivos que explican por qué en un territorio se dan formas más o menos sólidas y permanentes de cooperación, no son fáciles de dilucidar. Diferentes factores, como la confianza, la tolerancia al riesgo que conlleva compartir decisiones, o la solidaridad, se combinan para explicar el desarrollo de la cooperación. Pero por qué en un territorio y en un momento determinado, estos factores se han desarrollado y han facilitado la cooperación, es algo difícil de explicar. 
En su gran mayoría, las reflexiones sobre el desarrollo local, dan cuenta de estos fenómenos una vez producidos, como constatación a posteriori. (Cavestany 2005: 6)

En el departamento de Cundinamarca y la ciudad capital del país, Bogotá, claramente se refrenda de manera positiva la concomitancia entre la cooperación internacional y la gestión en las instituciones públicas. En ambos, la presencia de diversos estamentos y organismos de cooperación internacional de diversos matices, los ubican en un lugar de privilegio en cuanto a la disposición, pero igualmente, del provecho que han tomado de ellos por tenerlos como núcleo estamental complementaria a la administración regional y local. Además, que con la convergencia de dichos estamentos en la capital, esta se convierte en una gran promotora de la cooperación, que debe ser entre tanto apreciada por los diversos estamentos descentralizados del país.

Al contar con la oferta de agencias de cooperación que brinda la capital y con ella, la posibilidad de encontrarlas a todas en un mismo lugar, hace falta en los departamentos y municipios del país una amplia coordinación para entender que si bien hay disentimientos con referencia a la centralidad, está es una de las ventajas que expone dicho proceso, cuanto al amparo de la perspectiva realista de los Estados, estos comprenden a la par que las instituciones cooperadoras que el aprovechamiento de los recursos parte precisamente de la no existencia desproporcional de divisiones o unidades, que en este caso, envilezcan el propósito de la cooperación, confinándola a eslabones burocráticos y estamentales que reducirían sus buenos oficios. (Ver cuadro 3).

\section{Cuadro 3. Visión de la cooperación descentralizada definida por la ciudad}

\begin{tabular}{|l|l|}
\hline $\begin{array}{l}\text { Definición de Cooperación } \\
\text { Descentralizada definidas } \\
\text { por la ciudad }\end{array}$ & \\
\hline $\begin{array}{l}\text { Cooperación descentrali- } \\
\text { zada }\end{array}$ & $\begin{array}{l}\text { Ayuda al desarrollo que se canaliza desde las adminis- } \\
\text { traciones públicas. }\end{array}$ \\
\hline $\begin{array}{l}\text { Cooperación descentraliza- } \\
\text { da pública-CDP }\end{array}$ & $\begin{array}{l}\text { Subdivisión de la Cooperación: “Conjunto de acciones } \\
\text { de Cl que promueven los gobiernos locales y regiona- } \\
\text { les". Directa: Relación entre los gobiernos locales y re- } \\
\text { gionales. Indirecta; Acciones presentadas por una ONG } \\
\text { y financiados por los gobiernos sub-estatales. }\end{array}$ \\
\hline $\begin{array}{l}\text { Cooperación descentraliza- } \\
\text { da privada }\end{array}$ & $\begin{array}{l}\text { Brinda la oportunidad a sus homólogos de los países re- } \\
\text { ceptores, de asociarse (en forma de consorcios, uniones }\end{array}$ \\
\hline
\end{tabular}




\begin{tabular}{|c|l|}
\hline \multirow{2}{*}{ Herramientas } & $\begin{array}{l}\text { temporales, etc.,) para ejecutar proyectos que puedan } \\
\text { ser financiados por un tercero, ciudad, estado, organiza- } \\
\text { ción multilateral, empresas u ONG internacional. }\end{array}$ \\
\hline Redes & $\begin{array}{l}\text { Convenios suscritos entre dos ciudades, municipios o } \\
\text { provincias de países con intereses comunes (..) que bus- } \\
\text { can la definición de proyectos o actividades de coope- } \\
\text { ración que benefician a ambas partes. }\end{array}$ \\
\hline $\begin{array}{l}\text { Son asociaciones de expertos o ciudades que por medio } \\
\text { de alianzas estratégicas intercambian información, ex- } \\
\text { periencias o conocimientos o ejecutan proyectos con- } \\
\text { juntosy acciones coordinadas y estrategias por las partes. }\end{array}$ \\
\hline
\end{tabular}

Fuente: Estrategia de Cooperación Internacional de Bogotá, (Olaya y Vélez, p. 325)

Es de destacar seguidamente, el papel cumplido por la capital del país al abonar en sus propuestas de desarrollo todo los elementos que a bien cuenta sirven en la cooperación internacional, tanto central como descentralizada, entendiendo que con ellas en ningún caso se pretende descalificar la acción administrativa o de gestión de algún gobierno, por el contrario, se pretende inculcar la participación intergubernamental para enriquecer la capacidad de la gestión pública, refrendada en otros apartes por la calidad e impacto de las propuestas que sean atendidas al respecto en los planes de desarrollo, entre otros parágrafos, que a la par con el mencionado revisten trascendencia a la hora de evaluar las agendas públicas locales:

Podría afirmarse que los Departamentos colombianos se encuentran en una fase de planeación estratégica de la cooperación. Oportunidad única para incluir la gestión y promoción de proyectos a través de las distintas modalidades, entre ellas, la cooperación descentralizada. La coyuntura actual exige la profundización de la discusión y el papel activo de las asociaciones y entidades interesadas en el tema, para profundizar el conocimiento que tienen los gobiernos locales al respecto. La experiencia de Bogotá como Distrito Capital puede convertirse en poco tiempo en un ejemplo de "buenas prácticas" respecto a la gestión de la cooperación descentralizada en Colombia. (Olaya y Barbosa 2010:330).

Aunque los casos mencionados, solo son un reflejo de lo que crecientemente se está presentando en el país, no sobra precisar los eslabones que para el efecto requerirán las administraciones públicas territoriales a medida que internalicen la cooperación internacional central y descentralizada, como marco de caracterización y evaluación de la gestión pública, una vez interiorizada esta condición, el grado de compromiso advertido por las mismas instituciones territoriales para hacer de su administración estamentos abiertos a contemplar otros aportes y perspectivas, 
eventualmente podría ser ofertada por las fuentes de cooperación. No obstante, la expectativa es conocer por parte de todos ellos la estructura a la que apostarían para lograrlo. En el caso de este escrito se contempla el siguiente esquema. (Ver esquema 1).

\section{Esquema 1 Propuesta}

\section{Modelo de Cooperación Internacional Descentralizada en la Administración Departamental y Municipal en Colombia}

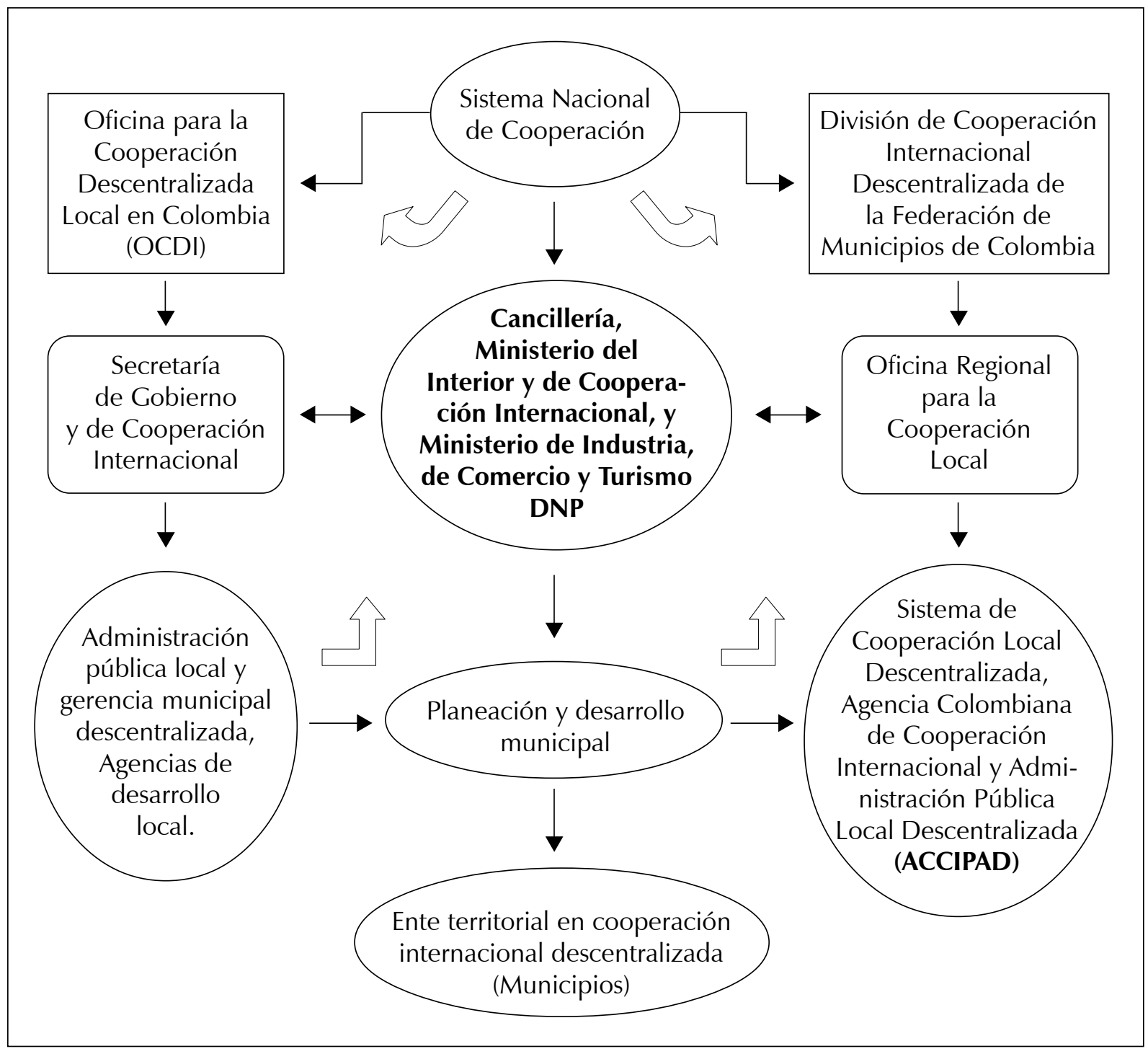

Fuente: Elaboración propia. 
El esquema planteado proyecta una relación de estamentos sobre los que debería reposar toda la operatividad de la cooperación internacional, central y descentralizada, conforme a las probabilidades ascendentes de hacer parte de las administraciones públicas territoriales, y como al paso del aumento de las relaciones internacionales, debería ordenarse y promoverse la interacción entre los diferentes entes que allí se mencionan. Por ser una proximidad de lo que se cree podría ser el planteamiento de la cooperación, requiere así mismo, de una explicación que en cierta medida la contemplase para entenderse de manera clara o revaluarse de ser el caso, como a continuación se considera:

\section{Sistema Nacional de Cooperación:}

En la Directiva 01 de 2008 fueron definidos los elementos para estructurar el Sistema Nacional de Cooperación. A dicha unidad pertenecen los departamentos con carácter de Ministerio como el Departamento Nacional de Planeación (DNP) y la Cancillería, con el propósito de promover la cooperación como parámetro de gestión municipal. Sin embargo, la batuta al respecto según la base del mismo sistema, sigue estando en la dirección de los elementos que defina el Estado central. De igual manera, hace parte de dicho Sistema el Consejo de Ministros. El sistema contiene en sus frentes la posibilidad de que las regiones y localidades puedan acercarse de manera directa para poder contar con la cooperación internacional en su estructura administrativa.

Oficina para la cooperación descentralizada local en Colombia (OCDI):

Apegada a los parámetros y criterios de la Cumbre de París de 1998, sobre cooperación local, y creada con el propósito de contribuir de una manera más directa al mejoramiento de la administración pública local, particularmente de la Unión Europea con los países de América Latina. Sería la unidad operativa de la cooperación descentralizada, por cuanto en ella deben descansar los programas y proyectos que hacia el exterior se conducirán para promocionar el desarrollo local y la misma gestión municipal. Tendría presencia en el Departamento Nacional de Planeación y los órganos de carácter territorial con perfil consultivo e informativo, más que decisorio. En este mismo frente haría parte del Consejo Territorial Departamental de Planeación, con las mismas tareas asignadas a escala nacional.

A escala internacional tendría participación directa en el Sistema Nacional de Cooperación, haciendo parte de los equipos de trabajo propositivos y consultivos por parte del Estado central, y de manera directa con la Presidencia de la República, y asumiría un carácter territorial, por cuenta de la necesidad de hacer consultas a las diferentes regiones y municipios sobre sus necesidades, con el ánimo de estructurar las necesidades que en la materia permitirían abordar los preceptos de cooperación entre los territorios las autoridades correspondientes, pero de igual forma los organismos de cooperación, foco de esta intención. 
División de Cooperación Internacional Descentralizada de la Federación de Municipios de Colombia:

La Federación de Municipios ha hecho enormes esfuerzos para contribuir a la estructuración de una política clara en materia de cooperación internacional descentralizada. La presencia en diferentes eventos internacionales así lo confirma. Son los municipios quienes deben tener más clara la idea al proponer proyectos en esta materia. De esta manera, es necesario que se determine hacia donde irán los temas de creación de regiones o grandes regiones territoriales previstas en la misma Constitución.

Esta entidad compuesta por la mayoría de alcaldes del país, entiende que se tendrá un rol protagónico dentro de la administración local en Colombia. Sin embargo, uno de los factores para que dicha posibilidad sea cierta es el de abandonar el componente político electoral, y proponerse a gestionar lo político desde lo público, puesto que al final las relaciones internacionales en materia de cooperación no prestan atención a los intereses de poder sino a los de los ciudadanos.

Cancillería, Ministerio del Interior y de Cooperación Internacional, y Ministerio de Industria, Comercio y Turismo, Departamento Nacional de Planeación (DNP):

Corresponde a la estructura institucional del Estado en Colombia ser actor catalizador entre las concepciones que tenga el Estado en materia de cooperación internacional, y cooperación descentralizada, y entre lo que finalmente pueden generar los territorios locales y municipales en la materia. Esta composición debe tener sumo cuidado, dado que su campo de acción corresponde a diferentes intereses, en donde no es clara la presencia de los ministerios, que por su propósito no deben estar o no tienen realmente ninguna incidencia en dichos temas.

Dentro de la Carta de Información del Programa URB-AL, se expone lo siguiente:

La cooperación descentralizada, asimismo, ha supuesto para los entes de gobierno local (y en cierta forma para otros actores locales) un contrapeso frente a las inercias del centralismo político y económico de los países. Al abrir caminos viables de internacionalización y de puesta en contacto con entes de gobierno y agentes sociales organizados de otros países, su concurso no ha sido despreciable en la sinuosa ruta del ejercicio de la autonomía municipal. Este contrapeso no radica necesariamente en los recursos financieros que aportan los proyectos de la cooperación descentralizada, sino sobre todo en los efectos demostración de que esta última es portadora, así como en las sinergias que se producen cuando los factores territoriales cuentan con posibilidades de ser puestos en valor. (Carta de Información del Programa URB-AL, 2004, p. 14).

La idea de contar con el nombre de cooperación internacional descentralizada acompañada del Ministerio del Interior tiene el propósito de ponerle sello a la gestión del orden central. Para lo 
que viene, la idea de un Estado proponente y gestor de los temas de cooperación, al igual que las fuentes para su propósito, está siendo reemplazada en un grado alto por niveles de observancia, más que de vigilancia y control, bases sobre las cuales deberá apoyarse el Estado en Colombia, no solo para canalizar sino hacer posible la (CID) para los entes territoriales del país. De esta manera, se puede sustentar lo siguiente:

Los procesos de globalización que caracterizan las sociedades contemporáneas están propiciando la redefinición del papel de los Estados y de sus gobiernos en los distintos ámbitos de actuación. En el contexto latinoamericano, los procesos de transformación del rol que juegan los gobiernos han tenido un reflejo tanto en las funciones que desarrollan como en las estrategias utilizadas para hacerlas efectivas. La frecuente falta de adecuación de las estructuras administrativas públicas tradicionales a este proceso de cambio, junto con las crisis políticas y económicas, han propiciado el surgimiento de programas de modernización y reforma de estos aparatos públicos. A resultas de ello, y desde hace y varias décadas, la modernización de las administraciones públicas parece ser un rasgo distintivo o consustancial a su propia existencia, apareciendo con cierta asiduidad en las agendas de los poderes públicos. La elaboración de estos programas de modernización también ha venido condicionada por los procesos de globalización, tanto a través de la consideración de referentes internacionales como mediante la actuación de agentes transnacionales que han actuado como vehículos de difusión institucional. (Salvador, 2003, p. 1).

Secretaria de Gobierno y de Cooperación Internacional:

Sería la instancia local por parte de los entes municipales que debe tener una capacidad de acción mucho más poderosa que los entes de carácter nacional. La cooperación dejaría de ser un campo subsidiario de la administración local, pasando a ser un campo palpable y visible de la administración municipal. Esta Secretaría tendría la capacidad de moverse internacionalmente, con el ánimo de acercar las directrices municipales en dicha área con las que se ofrecen en el exterior. Dejando la labor del alcalde a una acción más directa con la localidad, y menos demostrativa a través de actos e inauguraciones. Es decir, mientras que la Secretaría gestiona en el exterior, el alcalde debe preparar la casa para recibir la visita de los interesados o convocados para hacer parte de la gestión municipal descentralizada, con el concurso de la cooperación internacional. Debe haber suma claridad en cuanto al papel del alcalde y del secretario de gobierno para que los mal acostumbrados celos políticos no opaquen la labor de ambos por el hecho de figurar, quien debe figurar es el municipio no el alcalde u otro representante público. El municipio es el que debe ser destacado.

Oficina regional para la cooperación local:

Lazo de unión entre lo regional, lo nacional y lo local, dado que la idea es preservar la estructura departamental, puesto que la cooperación descentralizada no conduce a la división plena, sino 
por el contrario, a la articulación de todos los componentes que constituyen lo territorial, en donde incluye la relación interdepartamental e intermunicipal. La idea de este esfuerzo es no caer en duplicidades o ambigüedades a la hora de hacer gestión regional, por ende, debe existir un organismo que no solo articule sino que coordine la gestión de cada uno de los entes, convirtiendo la ventaja y las condiciones que obtengan algunos entes territoriales como punto de partida para otros.

Administración pública local y gerencia municipal descentralizada:

Dado que en Colombia se promulga la idea de las áreas metropolitanas, el propósito de este tipo de órgano sería el de ordenar y coordinar las labores de cooperación descentralizada entre municipios cercanos o frontera, en temas claramente de interés común por su cercanía o correspondencia geográfica. Se habla de una gerencia, dado que el crecimiento del proceso depende de las propuestas que cada municipio proponga al respecto, es decir, que se preservaría la idea de hacer gestión por medio de la cooperación descentralizada con proyectos, muestra que la tarea en dicha materia aún es reciente, y más en las diferentes acciones que dicha relación con organismos internacionales generaría, en materia de tipos, formas y estructuras de diseño, proyección y promoción de un proyecto a escala internacional.

Planeación y desarrollo municipal:

Componente de dirección y control en cuanto a los proyectos y acciones relacionadas con la cooperación descentralizad, sobre las líneas estratégicas que se definieran y aprobaran en los planes de desarrollo municipal. La idea con la Secretaría de Planeación sería la de analizar las condiciones de prioridades y necesidades integrales en materia de cooperación a través de las cuales se pudiese avanzar en cuanto a los temas de la gestión y la administración municipal. En ella, se espera que se puedan ampliar o crear iniciativas alrededor del Banco de Proyectos de Cooperación Internacional Descentralizada que a través del Departamento Nacional de Planeación (DNP), puedan ser impulsados por el mismo gobierno central, o en su defecto de las posibilidades locales que en últimas es el propósito real.

Sistema de cooperación local descentralizada: Agencia colombiana de Cooperación Internacional y administración pública local descentralizada (ACCIPAD):

Unidad cuyo fin sería el de promover la cooperación descentralizada interterritorial en el país en diferentes campos. La idea, es que también se muestre que la estructura territorial es capaz de ofrecer posibilidades internas de cooperación no solo cuando las partes cooperantes lo aprueban o demandan sino cuando existe la opción directa de que una localidad reciba el esfuerzo de una unidad territorial cercana, ya sea municipal o departamental. Es decir, la cooperación encarnaría su verdadero papel en cuanto a la gestión pública local no solo evidenciada en el 
esfuerzo propio sino en los derrames que dicha ventaja podría tener para comunidades y localidades con las mismas características.

Ente territorial en cooperación internacional descentralizada (Municipios):

La meta es concentrar todos los esfuerzos de la cooperación descentralizada en el municipio y los departamentos, porque las necesidades de cada uno al igual que sus condiciones les obligan a tomar la propuesta con suma responsabilidad pero más aún aplicación, siendo el tema central de la propuesta, dirigir los esfuerzos a estructurar la plataforma de cooperación descentraliza en Colombia a escala local y regional.

En general, la cooperación internacional descentralizada viene siendo promovida con el propósito de que los entes locales territoriales puedan explorar caminos que de manera autónoma y directa, les generen mejores resultados administrativos, gerenciales y públicos, toda vez que la gestión internacional que concebiría, podría conducir a éstos hacia otras posibilidades. Sin embargo, aunque el interés es plausible surgen preguntas que en el camino obligan a analizar la posibilidad de contar con la cooperación descentralizada no sólo como una fuente de recursos, sino como un mecanismo para medir la gestión territorial local siendo algunas de estas (Ver cuadro 4).

\section{Cuadro 4. Cuestionamientos a la Cooperación Internacional Descentralizada.}

¿Si la comunidad entiende claramente para qué le podría servir la cooperación internacional?

¿Qué exigencias se harían a la administración pública para hacer de la cooperación descentralizada un órgano de eficiencia en la gestión local?

¿Cómo se prepararía a la comunidad para aprovechar la cooperación descentralizada?

¿Bajo qué esquemas atendería la administración pública las consideraciones que hiciese la comunidad acerca de la cooperación descentralizada?

¿Cómo se demostraría que la cooperación descentralizada sirve para que las administraciones públicas territoriales asciendan en su gestión?

¿Bajo qué ideas el Estado procuraría fomentar la cooperación descentralizada en los municipios?, ¿cuál sería el acuerdo o las exigencias al respecto al interior de su idea de unidad nacional o de poder central? 
¿Cómo, quiénes, y bajo qué preceptos se procuraría desarrollar una Secretaría de la Cooperación Internacional en los municipios?

¿Cómo estas Secretarías trabajarían de la mano con la estructura diplomática y de misiones extranjeras residentes y extranjeras al igual que con la Cancillería?

¿Podría considerarse este tipo de propuestas como una forma real de agenciar internacionalmente un Estado como el colombiano, considerado desde la diplomacia como un Estado que carece de una política clara en la materia, pese a los últimos éxitos alcanzados?

Fuente: Elaboración propia.

La formulación de los planteamientos obedece a la necesidad de poner el tema en debate y discusión a escala de los entes centrales y territoriales, por cuanto, el tomar este campo como elemento transversal implica cambiar la filosofía no solo institucional sino de todo el estado. Por lo menos, la idea es que puedan ventilarse áreas en los que tenga cabida la presencia de estamentos de cooperación internacional en áreas en donde se vea optimizada las premisas que el Estado de manera central considere, en competencia con los entes territoriales, que tenga afluencia extranjera con matices claramente identificados.

\section{CONCLUSIONES}

La cooperación internacional descentralizada tiene la posibilidad de ordenar los esquemas de formulación institucional de los entes territoriales con miras a la evaluación y observancia internacional, toda vez, que la inscripción a fuentes de cooperación o promoción internacional tendrían como una de sus bases apreciar lo propuesto sobre dichos temas que acogieren a la cooperación como material susceptible de contemplarse en calidad de ejemplo internacional. Debe ser prioridad para los entes el continuar avalando sus acciones de manera interna, siendo una panacea para lo que significa la autoevaluación de lo hecho en diversos frentes.

El explorar el escenario de la cooperación internacional descentralizada conduciría a elevar los escalones de certificación internacional, en aras de optimizar las bases en que se desarrollan múltiples tareas de las administraciones públicas, que con buena dirección podrían tener asiento en las líneas de apoyo y de programas internacionales, en los que se contemplan intereses igualmente definidos al interior de los entes territoriales del país. Por ende, el papel que jugarían en adelante las hasta ahora unidades de cooperación internacional que se tienen a escala departamental y municipal sería crucial. 
En la capacidad de gestión internacional está en gran medida el futuro de la dirección territorial de los entes locales y regionales, para lo cual, es necesario definir un plan estratégico de orden nacional y descentralizado, a través del cual puedan definirse las dependencias y los mecanismos que de manera directa, contribuyan para materializar los alcances de la cooperación internacional descentralizada en cada nivel territorial. Es muy importante que se atienda este escenario, puesto que considerarlo como campo de solo interés central puede alejar aún más al país de las líneas y redes internacionales de cooperación que están adscritas en los mismos componentes que el país ha definido como impostergables, como el mejoramiento de la institucionalidad y la lucha contra la desigualdad e inequidad.

\section{BIBLIOGRAFÍA}

- Abalos K, J.A. El Papel de la cooperación al desarrollo en el actual Proceso de Descentralización.Fuente:http://www.revistacienciasociales.cl/archivos/revista1/word/ revista_1_art_5.doc,1 - 12.

- Agencia colombiana de Cooperación Internacional -ACCI- (2002). Doc. Institucionales Documentos de trabajo Colombia Joven.

- Carta de Información del Programa URB-AL (2004). Programa horizontal de cooperación descentralizada de la Comisión Europea, destinado a las ciudades, aglomeraciones y regiones de la Unión Europea y América Latina.

- Cavestany B., F. (2005). Desarrollo desde el territorio. A propósito del desarrollo local. Instituto Internacional de Gobernabilidad. Colección de Documentos. Biblioteca de IDEAS. http: //www.iigov.org.

- Cirera, Ana (2009). La evaluación de la política de cooperación: el impulso desde los organismos internacionales. XI Congreso Internacional del CLAD sobre la Reforma del Estado y de la Administración Pública, Ciudad de Guatemala.

- Del Huerto R., M. "Nuevos enfoques en la cooperación internacional". La cooperación descentralizada y el Programa URB-ALde la Comisión Europea, Coordinadora Red 7- Programa URB-AL.

- Dirección de Cooperación Internacional de la Agencia Presidencial para la Acción Social y la Cooperación Internacional -ACCI- (2007). Estrategia de cooperación internacional. 20072010, 1- 130. 
- Documento CONPES -2968 (1997). DNP. Nuevo enfoque de la cooperación internacional. Cooperación internacional/Cooperación económica colombiana. Bogotá, Nov, 1-123.

- Ferrari W., G. (2003). La necesidad de optimizar la cooperación internacional: algunas experiencias latinoamericanas. VIII Congreso Internacional del CLAD sobre la Reforma del Estado y de la Administración Pública, Panamá, 1-15.

- Garzón, L. E. (2008). Ex - Alcalde Mayor de Bogotá D.C. Los Gobiernos Locales en la Esfera Global. Consecuencias de la entrada de los gobiernos locales en el ámbito internacional. Ponencia para la III Conferencia Anual del Observatorio de Cooperación Descentralizada UEAL, 1-12.

- Gobernación de Antioquia (2010). Antioquia crea la primera red de cooperación internacional del país. Gerencia de comunicaciones - dirección de información y prensa. Despacho del Gobernador. Medellín, 12 abril de 2010 / Hora. 2: 00 p.m. Rueda de prensa: miércoles 14 de abril. Lugar: Salones 1 y 2 COMFAMA San Ignacio (piso4).

- Godínez, V. M. (1999). Economía política de la cooperación descentralizada: algunas consideraciones desde América latina. Economía Política de la cooperación descentralizada: Algunas consideraciones desde América latina CEE UNAM, 1-16.

- Olaya B., Sandra y Vélez R., Jeannette (2010). La cooperación descentralizada en Colombia: una primera aproximación a la visión de los Departamentos y la experiencia de Bogotá como Distrito Capital. Universidad del Rosario, Bogotá, Estudios de casos, 307-330.

- Palomo P., S. (2000). La administración pública local como protagonista del futuro de la cooperación internacional al desarrollo a través de la cooperación oficial descentralizada. "Estrategia para la Cooperación española". SECIPI. Madrid, 1-9.

- Salvador S., M. (2003). El impacto de los referentes internacionales en la transformación de las administraciones públicas latinoamericanas: agentes y dinámicas institucionales. Panel: Entre la transformación de las administraciones públicas y la creación de nuevas fórmulas de gestión. La influencia de los referentes internacionales, VIII Congreso Internacional del CLAD sobre la Reforma del Estado y de la Administración Pública, Panamá, 2831, 1- 21.

- Torrijos, V. (2000). La diplomacia centrifuga. Preámbulo a una política exterior de las regiones., en Desafíos no 2, Bogotá, CEPI, Universidad del Rosario, 20- 21. 